\title{
Obez hastalarda düşük akım ve normal akım anestezisinin etkinlik ve güvenilirliğinin araştırılması: Randomize bir çalışma
}

\section{Investigation of the efficacy and safety of low-flow and normal-flow anesthesia in obese patients: A randomized trial}

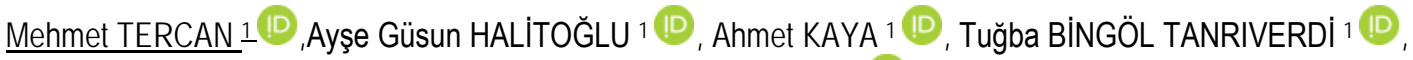 \\ Gülçin PATMANO1D
}

1Anesteziyoloji ve Reanimasyon, SBÜ Mehmet Akif İnan Eğitim ve Araştırma Hastanesi, Şanllurfa

\section{Öz.}

Amaç: Vücut kitle indeksinin 30 ve üstü değerleri obezite olarak tanımlanmaktadır. Obezlerde kilo ile beraber vücut yüzey alanı artar, böylece bazal metabolik hız normal kiloda olanlara kıyasla daha yüksek hale gelir. Düşük akım anestezisi (DAA), taze gaz akımının (TGA) 1L/dk'nın altında olduğu anestezi yöntemidir. Literatürde, laparoskopik cerrahi uygulanan obez hastalarda farklı gaz akımlarıın etkilerini karşılaştıran çalışmalar çok sınırıdır. Çalışmamızın amacı, düşük akım anestezisinin obez hastalardaki etkinlik ve güvenilirliğini incelemektir.

Materyal ve Metod: Bu randomize prospektif çalışmaya, laparaskopik kolesistektomi uygulanan, 18-65 yaş arası 100 hasta dâhil edildi. Randomizasyon için kapalı zarf yöntemi kullanıldı. DAA uygulaması TGA'nın 0.5 L/dk'dan verilmesi olarak tanımlanırken, normal akım anestezi (NAA) TGA'nın 2 L/dk'dan verilmesi olarak tanımlandı. 100 hasta randomize olarak 4 gruba ayrıldı. Grup 1: normal kilolu ve DAA uygulan hastalar, Grup 2: normal kilolu ve NAA uygulanan hastalar, Grup 3: obez olup DAA uygulan hastalar, Grup 4: obez olup NAA uygulan hastalar.

Bulgular: Çalışmaya dâhil edilen hastaların hiçbirinde entübasyon sonrası inspiratuar oksijen düzeyi (insO2) değeri \%35'in altına düşmedi. Dolayısıyla da hiçbir hastada hipoksi gözlenmedi. Bununla beraber; grup 2 hastalar ile karşılaşııııldığında, grup 1 hastalarında anestezi süresi anlamlı olarak daha uzun iken, desflurane tüketimi ise anlamlı olarak daha az idi. Benzer şekilde, grup 4 hastalar ile karşılaştırıldığında, grup 3 hastalarında anestezi süresi anlamlı olarak daha uzun iken, desflurane tüketimi ise anlamlı olarak daha az idi. Sonuç: Çalışmamızdan elde edilen bulgular DAA uygulamasının normal kilolu hastalarda olduğu gibi, obez hastalarda da güvenle kullanılabileceğini ve maliyeti düşürmede etkili bir yöntem olduğunu düşündürmektedir.

Anahtar sözcükler: Düşük akım anestezi, Laparaskopik kolesistektomi, Obezite

\section{Abstract}

Background: Body mass index values $\geq 30$ are defined as obesity. In obese, body surface area increases with weight; thus, the basal metabolic rate becomes higher compared to those at normal weight. Low-flow anesthesia (LFA) is an anesthetic method where fresh gas flow (FGF) is less than $1 \mathrm{~L} / \mathrm{min}$. There are limited studies in the literature comparing the effects of different gas flows in obese patients undergoing laparoscopic surgery. The aim of this study was to investigate the efficacy and safety of LFA in obese patients.

Materials and Methods: This randomized prospective study included 100 patients aged between 18-65 years undergoing laparoscopic cholecystectomy. Sealed envelope method was used for randomization. LFA was defined as the administration of FGF at $0.5 \mathrm{~L} / \mathrm{min}$, while normal flow anesthesia (NFA) was defined as FGF at 2 L/min. 100 patients were randomly divided into 4 groups. Group 1: normal patients with weight and LFA, Group 2: normal patients with weight and NFA, Group 3: obese patients and LFA, Group 4: obese patients with and NFA.

Results: None of the patients had an inspiratory oxygen level (insO2) value below 35\% after intubation. Therefore, hypoxia was not observed in any patient. However; when compared to group 2, group 1 had significantly longer anesthesia time and lower desflurane consumption. Similarly, when compared to group4, group 3 had significantly longer anesthesia time and lower desflurane consumption.

Conclusion: Our results suggest that LFA can be used safely in obese patients as well as in normal weight patients and it is an effective method to reduce the cost.

Keywords: Low flow anesthesia, Laparoscopic cholecystectomy, Obesity

\section{Sorumlu Yazar I \\ Corresponding Author}

\section{Dr. Mehmet Tercan \\ Anesteziyoloji ve Reanimasyon, \\ SBÜ Mehmet Akif İnan Eğitim \\ Araştırma Hastanesi \\ Esentepe mah.Haliliye/Şanlıurfa}

\section{email:mehmet.tercan@sbu.edu.tr \\ Tel:05323445635}

Geliş tarihi / Received:
03.09.2019

Kabul tarihi / Accepted:

25.10.2019

DOI: 10.35440/hutfd.614532 


\section{Giriş}

Dünya sağlık örgütü; vücut kitle indeksinin (VKi) 30 ve üstü değerlerini obezite olarak tanımlamaktadır. Obezlerde kilo ile beraber vücut yüzey alanı artar, böylece bazal metabolik hız normal kiloda olanlara kıyasla daha yüksek hale gelir. Yapılan çalışmalarda, obezitenin yaşam kalitesini ve süresini olumsuz etkilediği ve aşırı sağlık harcamalarına yol açtığı gösterilmiştir (1-3).

Düşük akım anestezisi (DAA), taze gaz akımının (TGA) 1L/dk' nın altında olduğu anestezi yöntemidir (4). DAA kullanımının, maliyette azalma, çevre kirliliğinin önlenmesi, gazların nemlenmesinde artış, ısı kaybının azalması yanında trakeal ve bronş fizyolojisinin daha iyi korunması gibi birçok faydası olduğu bilinmektedir (5). Ancak, DAA kullanımında hekimlerin dikkat etmesi gereken bazı önemli durumlar mevcuttur. Bunların en önemlisi intraoperatif dönemde gelişebilecek hipoksidir (6). Obezlerde bazal metabolik hızın artmasına bağlı olarak oksijen intiyacı artmış olduğu için, intraoperatif hipoksi görülme sıklı̆ı artabilir $(7,8)$.

Günümüzde gelişen tıbbi teknikler ile birlikte laparoskopik cerrahi birçok alanda açık cerrahiye göre daha çok tercih edilen bir tedavi yöntemi haline gelmiştir. Hızlı yara yeri iyileşmesi, daha küçük cerrahi insizyon alanı ve daha kısa hastanede kalış süresi laparoskopik yöntemin başlıca avantajlarındandır (9). Ancak, laparoskopik cerrahide meydana getirilen pnömoperitonyumun, pulmoner sistem üzerine hem kimyasal hem de mekanik bazı olumsuz etkileri vardır. Abdominal kavitenin $\mathrm{CO}_{2}$ ile insüflasyonuyla, karın içi basıncı artar ve bu durum diyaframın yukarı doğru distansiyonuna neden olur. Bu distansiyon intratorasik basıncı arttırarak alveoler kollapsa neden olabilir $(10,11)$. Bu tablo hipoksiye zemin hazırlayabilir.

Desfluran; kan ve vücut dokularında düşük çözünürlük, hızı anestezi indüksiyonu, geniş doz aralığı ve çabuk derlenme gibi avantajlara sahip olduğu için düşük akım anestezide en sık tercih edilen volatilanestezik ajandır $(12,13)$. Literatürde, laparoskopik cerrahi uygulanan obez hastalarda farklı gaz akımlarının etkilerini karşılaşııran çalışmalar çok sınırlıdır. Çalışmamızın amacı, düşük akım anestezisinin obez hastalarda güvenle kullanılıp kullanılamayacağını belirlemektir. Ek olarak, düşük akım anestezisinin maliyet üzerindeki etkisi de değerlendirilecektir.

\section{Materyal ve Metod \\ Hasta seçimi}

Çalışmamıza yerel etik kurul onamı alındıktan (no: 18/5/16) ve klinik çalışma kaydı yapıldıktan sonra (ACTRN12618000943246) başlandı. Tüm hastalara çaıışma hakkında bilgi verilerek yazıı onamları alındı. Bu randomize prospektif çalışmaya, laparaskopik kolesistektomi uygulanan, American Anestezistler Derneği (ASA) skoru 1-2 olan, 18-65 yaş arası 100 hasta dâhil edildi. ASA III-IV, sigara içen, kronik obstriktif akciğer hastalığı, kardiyak, renal ve karaciğer hastalığı olanlar ve zor entübasyon olguları çalışma dışı bırakıldı.

\section{Randomizasyon}

Çalışmamız, randomizeprospektif bir çalışma olarak tasarlandı. Randomizasyon için kapalı zarf yöntemi kullanıdı. 100 hasta randomize olarak 4 gruba ayrıldı. Grup 1: normal kilolu ve DAA uygulan hastalar, Grup 2: normal kilolu ve NAA uygulanan hastalar, Grup 3: obez olup DAA uygulan hastalar, Grup 4: obez olup NAA uygulan hastalar. VKi'nin < 30 olduğu hastalar normal kilolu olarak adlandırılırken, VKI'nin $\geq 30$ olduğu hastalar obez olarak adlandırıldı. DAA, taze gaz akımının (TGA) 1L/dk 'nın altında olduğu anestezi şekli olarak tanımlanırken, NAA ise TGA'nın $\geq 2 \mathrm{~L} / \mathrm{dk}$ olduğu anestezi şekli olarak tanımlandı.

\section{Anestezi Yönetimi}

Hastalar operasyon odasına alındıktan sonra monitörize edildi ve elektrokardiyografi (EKG), periferik oksijen satürasyonu $\left(\mathrm{SpO}_{2}\right)$ ve noninvaziv yöntemle kan basıncı takipleri yapıldı. Tüm hastalarda aynı marka anestezi cihazı (Dräger perseus A500) ve taze karbondioksit absorbanı kullanıldı. İlaç ve tidal volüm uygulamalarında düzeltilmiş vücut ağırlığı formülü kullanıldı. Tüm anestezi uygulamaları deneyimli bir anestezi uzmanı tarafindan uygulandı. 35 dakika pre-oksijenizasyon sonrası $\left(4 \mathrm{~L} / \mathrm{dk} 100 \% \mathrm{O}_{2}\right)$, 2$3 \mathrm{mg} / \mathrm{kg}$ propofol, $1-2 \mu \mathrm{g} / \mathrm{kg}$ fentanil ve $0.6 \mathrm{mg} / \mathrm{kg}$ roküronyum ile anestezi indüksiyonu yapıldı. Anestezi indüksiyonundan sonra, hastalar endotrakeal entübe edilerek anestezi cihazına bağlandı. Hastalar tidal volüm 6-8 ml $/ \mathrm{kg}$, endtidal karbondioksit $\left(\mathrm{ETCO}_{2}\right) 30-35 \mathrm{mmHg}$ olacak şekilde ventile edildi. Anestezi idamesi için volatil ajan olarak desflurane kullanıldı. Minimum alveolar konsantrasyon (MAK) +1 oluncaya kadar TGA $2 \mathrm{~L} / \mathrm{dk}\left(1 \mathrm{~L} / \mathrm{dk} \mathrm{O}{ }_{2}-\right.$ $1 \mathrm{~L} / \mathrm{dk}$ hava) ve desfluran volümü $\% 12$ olarak ayarlandı. MAK1'e ulaştıktan sonra, NAA uygulanlarda TGA 2 L/dk'dan $\left(\mathrm{FiO}_{2}\right.$ : \%50 - Hava: \%50) devam ederken, DAA uygulananlarda TGA $0.5 \mathrm{~L} / \mathrm{dk}\left(\mathrm{FiO}_{2}: \% 80\right.$ - Hava: \%20) olacak şekilde devam edildi. Anestezi idamesinde desfluran volümu MAK1 olacak şekilde ayarlandı. Tüm hastalara postoperatif analjezi amaçlı 1-1.5 mg/kg tramadol, 15 $\mathrm{mg} / \mathrm{kg}$ parasetamol i.v. infüzyon şeklinde ekstübasyondan yaklaşık olarak 30 dakika önce uygulandı. Operasyon sırasında kese çıkarıldıktan ve hemostaz sağlandıktan sonra, vaporizör kapatıldı. Ardından hem NAA hem de DAA hastalarında TGA 4 L/dk'ya çıkarılarak \%100 oksijenizasyon yapıldı. Daha sonra, nöromüsküler blokajı geri çevirmek için atropin sülfat $(0.015 \mathrm{mg} / \mathrm{kg})$ ve neostigmin (0.03 $\mathrm{mg} / \mathrm{kg}$ ) yapılarak hastalar ekstübe edildi. İşlem sırasında herhangi bir komplikasyon gelişmedi.

\section{Ölçümler}

Tüm hastaların preoperatif, entübasyon sonrası 1., 3 ., 5.,10. ve sonraki her 5 dakikada bir kalp atım hızı (KAH), $\mathrm{SpO}_{2}$ ve ortalama arter basıncı (OAB) değerleri kaydedildi. Bunlara ek olarak, tüketilen $\mathrm{O}_{2}$ miktarlarını belirlemek 
için inspiratuar oksijen miktarı (insO $\mathrm{O}_{2}$ ) ve oksijen tüketim miktarı entübasyon sonrası her 5 . dakikada bir kaydedildi. Ayrıca MAK1'e ulaşma zamanı, anestezi süreleri ve desflurane tüketim miktarları kaydedildi.

\section{Istatistiksel Analiz}

Çalışmamızda elde edilen bulguların değerlendirmesinde SPSS (Statistical PackageforSocialSciences) for Windows 23.0" (SPSS Inc., an IBM Company, Chicago, USA) programı kullanıldı. Normal dağılım Kolmogorov Smirnov testi ile değerlendirildi. Sürekli değişkenlerin tanımlayıcı istatistiklerinde ortalama \pm Standart Sapma; kategorik değişkenlerin tanımlayıcı istatistiklerinde sayı ve yüzdeler kullanıldı. İkili grup karşılaştırmalarında normal dağılım göstermeyen gruplar için Mann Whitney-U testi kullanıldı. Kategorik değişkenlerde gruplar arası karşılaştırmalarda Ki-Kare testi kullanıldı. Ölçümlerin gruplardaki farklılıkları çizgi grafikler ile gösterildi. $p<0.05$ değeri istatistiksel olarak anlamlı kabul edildi.

\section{Bulgular}

Çalışmamıza toplamda 100 hasta dâhil edildi. Hastalara ait bazal demografik özelliklerin karşılaşııııması Tablo 1'de gösterilmektedir. ASA 1 sıklığı, grup 1 hastalarda grup 2 hastalara göre anlamlı olarak daha fazlaydı (\%52'ye karşın \%20, $P=0.018)$. Yaş açısından bakıldığında ise, grup 3'teki hastaların yaş ortalaması grup 4 hastalarına göre anlamlı daha yüksek idi (48.7 \pm 12.4 'e karşın $39.6 \pm 15.5, P=0.039$ ) (Tablo 1).

Tablo 1. Hastaların demografik verilerinin karşılaştırılması

\begin{tabular}{|c|c|c|c|c|c|c|}
\hline & $\begin{array}{l}\text { Grup 1 } \\
(n=25)\end{array}$ & $\begin{array}{l}\text { Grup 2 } \\
(n=25)\end{array}$ & $P$ & $\begin{array}{l}\text { Grup 3 } \\
(n=25)\end{array}$ & $\begin{array}{l}\text { Grup 4 } \\
(n=25)\end{array}$ & $P$ \\
\hline Yaş (yıl) & $\begin{array}{l}41.9 \pm \\
13.3\end{array}$ & $\begin{array}{ll}48.5 & \pm \\
12.5 & \end{array}$ & 0.080 & $\begin{array}{l}48.7 \quad \pm \\
12.4\end{array}$ & $\begin{array}{ll}39.6 \quad \pm \\
15.5\end{array}$ & 0.039 \\
\hline $\begin{array}{l}\text { Kadın cinsiyet } \\
(\%)\end{array}$ & $14(56)$ & $14(56)$ & 0.612 & $21(84)$ & $24(96)$ & 0.349 \\
\hline VKí (kg/m²) & $\begin{array}{l}23.3 \pm \\
1.6\end{array}$ & $\begin{array}{l}24.2 \quad \pm \\
0.8\end{array}$ & 0.050 & $\begin{array}{l}34.1 \quad \pm \\
4.2\end{array}$ & $33 \pm 2.6$ & 0.515 \\
\hline ASA skoru (\%) & & & 0.018 & & & \\
\hline $\begin{array}{l}1 \\
2\end{array}$ & $\begin{array}{l}13(52) \\
12(48)\end{array}$ & $\begin{array}{l}5(20) \\
20(80)\end{array}$ & & $-\overline{25(100)}$ & $-\overline{25(100)}$ & \\
\hline
\end{tabular}

Hastaların preoperatif ve intraoperatif dönemde kaydedilen hemodinamik parametreleri Şekil 1A-C'de gösterilmektedir. Gruplar arasında, $\mathrm{KAH}, \mathrm{OAB}$ ve $\mathrm{SpO}_{2}$ değerleri açısından anlamlı bir farklıık tespit edilmedi.

Entübasyon sonrası olguların hiçbirinde $\mathrm{ins}_{2}$ değeri $\% 35$ 'in altına düşmedi. Hastaların $\mathrm{SpO}_{2}$ değerleri de bununla uyumlu olarak \% 98 ve üstü olarak ölçüldü. Dolayısıyla da hiçbir hastada hipoksi gözlenmedi (Tablo 2).

Entübasyon sonrası oksijen kullanım miktarlarının gruplara göre dağılımı Tablo 3'te gösterilmektedir. Grup 2 hastalar ile karşılaştırıldığında, Grup 1 hastalarında 5. 15. 20. 25. 40. ve 45. dakikalarda oksijen kullanım miktarlarının anlamlı olarak daha düşük olduğu tespit edildi. Ek olarak, Grup 4 hastalar ile karşılaştıııldığında, Grup 3 hastalarında 10. 25. 30. ve 35. dakikalarda oksijen kullanım miktar- larının anlamlı olarak daha düşük olduğu tespit edildi (Tablo 3).

Tablo 2.Inspiratuar $\mathrm{O}_{2}$ (insO $\mathrm{O}_{2}$ ) değerlerinin gruplara göre dağı-

\begin{tabular}{|c|c|c|c|c|}
\hline $\begin{array}{l}\text { Entübasyon } \\
\text { sonrası Zaman/dk }\end{array}$ & $\begin{array}{l}\text { Grup 1 } \\
(n=25)\end{array}$ & $\begin{array}{l}\text { Grup 2 } \\
(n=25)\end{array}$ & $\begin{array}{l}\text { Grup 3 } \\
(n=25)\end{array}$ & $\begin{array}{l}\text { Grup 4 } \\
(n=25)\end{array}$ \\
\hline 5 & $67.1 \pm 1.5$ & $40.7 \pm 1.7$ & $66.9 \pm 1.2$ & $40.2 \pm 1.6$ \\
\hline 10 & $65 \pm 1.5$ & $40.2 \pm 1.3$ & $64 \pm 1.2$ & $39.4 \pm 1.4$ \\
\hline 15 & $63.1 \pm 1.6$ & $40 \pm 1.1$ & $62 \pm 1.5$ & $39.5 \pm 1.1$ \\
\hline 20 & $61.7 \pm 1.8$ & $39.6 \pm 1.1$ & $60.2 \pm 1.8$ & $39.2 \pm 1.9$ \\
\hline 25 & $61.8 \pm 7.1$ & $39.5 \pm 1.2$ & $58.7 \pm 2.4$ & $39.1 \pm 1.3$ \\
\hline 30 & $59.7 \pm 2.9$ & $39.6 \pm 1.2$ & $57.6 \pm 2.6$ & $39 \pm 1.4$ \\
\hline 35 & $58.7 \pm 3.7$ & $39.5 \pm 1.3$ & $56.5 \pm 3.2$ & $39 \pm 1.5$ \\
\hline 40 & $57.9 \pm 4.1$ & $39.5 \pm 2.1$ & $55.7 \pm 3.5$ & $38.7 \pm 1.4$ \\
\hline 45 & $54.7 \pm 12.1$ & $39.2 \pm 1.2$ & $54.8 \pm 4$ & $38.4 \pm 1.2$ \\
\hline 50 & $56 \pm 4.5$ & $39 \pm 1.3$ & $54.4 \pm 4.2$ & $38.4 \pm 1.2$ \\
\hline 55 & $55 \pm 4.9$ & $39 \pm 1.2$ & $52.7 \pm 4.2$ & $37.8 \pm 1.9$ \\
\hline 60 & $54.3 \pm 5.6$ & $39.7 \pm 0.6$ & $51.8 \pm 4.8$ & $37 \pm 1.4$ \\
\hline 65 & $57.3 \pm 5.7$ & $39.5 \pm 0.7$ & $50.8 \pm 5.5$ & 36 \\
\hline 70 & $57.3 \pm 6.7$ & 40 & $48 \pm 7.2$ & 35 \\
\hline 75 & 51 & - & $50.3 \pm 6$ & - \\
\hline 80 & 51 & - & $50 \pm 6.3$ & - \\
\hline 85 & 51 & - & $44.5 \pm 0.7$ & - \\
\hline 90 & - & - & - & . \\
\hline
\end{tabular}

Grup 2 hastalar ile karşılaştııılı̆̆ında, Grup 1 hastalarında anestezi süresi anlamlı olarak daha uzun iken, desflurane tüketimi ise anlamlı olarak daha az idi. Benzer şekilde, Grup 4 hastalar ile karşılaştırıldığında, Grup 3 hastalarında hastalarında anestezi süresi anlamlı olarak daha uzun iken, desflurane tüketimi ise anlamlı olarak daha az idi. Grup 1 ve grup 2 arasında MAK 1'e ulaşma zamanı açısından anlamlı bir farklıık tespit edilmezken, grup 3 hastalarında MAK 1'e ulaşma zamanı grup 4 hastalarına göre anlamlı olarak daha kısa idi (Tablo 4).

Çalışmaya alınan olgularda en sık görülen komplikasyon bulantı-kusmaydı $(n=6)$. Gruplar arasında komplikasyonlar açısından anlamlı bir farklılık tespit edilmedi. Ek olarak, hiçbir hastada hipoksi gelişmemiştir (Tablo 5).

\section{Tartışma}

Çalışmamızın ana bulgusu normal kilolu hastalarda olduğu gibi, obez hastalarda da düşük akım anestezisinin güvenle kullanılabileceğinin gösterilmiş olmasıdır. Bilgilerimize göre çalışmamız, laparoskopik kolesistektomi uygulanan obez hastalarda düşük akım ve normal akım anestezisinin etkilerini karşıllaştıran ilk çalışmadır.

Obezite, yaşam kalitesini ve süresini olumsuz etkileyen ve son yıllarda sıklığı giderek artan önemli sağlık sorunlarından birisidir. 
Tablo 3. $\mathrm{O}_{2}$ alım miktarının gruplara göre dağılımı

\begin{tabular}{|c|c|c|c|c|c|c|}
\hline $\begin{array}{l}\text { Entübasyon } \\
\text { sonrası } \\
\text { zaman/dk } \\
\end{array}$ & $\begin{array}{l}\text { Grup 1 } \\
(n=25)\end{array}$ & $\begin{array}{l}\text { Grup 2 } \\
(n=25)\end{array}$ & $P$ & $\begin{array}{l}\text { Grup 3 } \\
(n=25)\end{array}$ & $\begin{array}{l}\text { Grup 4 } \\
(n=25)\end{array}$ & $P$ \\
\hline 5.dk & $181.4 \pm 72.9$ & $234.4 \pm 81.4$ & 0.015 & $211.3 \pm 80.2$ & $226.2 \pm 63.9$ & 0.190 \\
\hline 10.dk & $203.8 \pm 75$ & $242.1 \pm 79.7$ & 0.081 & $211.5 \pm 71.4$ & $254.2 \pm 99.8$ & 0.043 \\
\hline 15.dk & $183.2 \pm 63.2$ & $\begin{array}{l}228.9 \pm 97.2 \\
243.6 \pm\end{array}$ & 0.047 & $216.3 \pm 83.6$ & $227.2 \pm 62.1$ & 0.118 \\
\hline 20.dk & $172.2 \pm 40.5$ & 103.8 & 0.003 & $223.7 \pm 83.7$ & $233.4 \pm 87.1$ & 0.056 \\
\hline 25.dk & $187.6 \pm 74.4$ & $259.6 \pm 99.6$ & 0.011 & $222.2 \pm 70.3$ & $248.6 \pm 76.3$ & 0.026 \\
\hline 30.dk & $214.1 \pm 65$ & $\begin{array}{l}244.2 \pm 113 \\
268.4 \pm\end{array}$ & 0.455 & $230.8 \pm 81.9$ & $250.7 \pm 68.6$ & 0.035 \\
\hline 35.dk & $222.1 \pm 65.3$ & $\begin{array}{l}103.9 \\
290.2 \quad \pm\end{array}$ & 0.133 & $225.9 \pm 68.3$ & $257 \pm 75.5$ & 0.026 \\
\hline 40.dk & $225.6 \pm 71.4$ & 124.5 & 0.043 & $243.7 \pm 70.5$ & $262 \pm 87.2$ & 0.226 \\
\hline 45.dk & $226.9 \pm 57$ & $281.4 \pm 90.9$ & 0.043 & $261.6 \pm 92.9$ & $260.9 \pm 76.1$ & 0.617 \\
\hline 50.dk & $\begin{array}{l}232.1 \pm 75.3 \\
271.8 \pm\end{array}$ & $\begin{array}{l}271.6 \pm 82.8 \\
297.8 \pm\end{array}$ & 0.129 & $270.1 \pm 97.1$ & $255.6 \pm 68.1$ & 0.771 \\
\hline 55.dk & $\begin{array}{l}105.4 \\
289.9\end{array}$ & 111.8 & 0.496 & $331.2 \pm 65.1$ & $275.3 \pm 87.6$ & 0.413 \\
\hline 60.dk & 175.9 & $\begin{array}{l}294.3 \pm 94.3 \\
297.1 \pm\end{array}$ & 0.345 & $303.7 \pm 87.2$ & $231.5 \pm 17.7$ & 0.800 \\
\hline 65.dk & $217.7 \pm 60.3$ & 110.6 & 0.279 & $336 \pm 147.1$ & 226 & 0.667 \\
\hline 70.dk & $238.3 \pm 95.5$ & $\begin{array}{l}340 \pm 130.1 \\
312.3 \pm\end{array}$ & 0.393 & 390 & 275 & 1.000 \\
\hline 75.dk & 371 & $\begin{array}{l}107.9 \\
349.5\end{array}$ & 1.000 & - & - & - \\
\hline 80.dk & 429 & 146.4 & 1.000 & - & - & - \\
\hline 85.dk & 417 & $296.5 \pm 71.4$ & 0.667 & - & - & - \\
\hline 90.dk & - & - & - & . & - & - \\
\hline
\end{tabular}

Obezlerde artan vücut yüzey alanı ile beraber, bazal metabolik hiz normal kilolu hastalara göre artar. Ek olarak, fonksiyonel rezidüel kapasite ve ekspiratuvar rezerv volüm azalırken, havayolu direnci de artar. Tüm bu değişiklikler obez hastalarda intraoperatif dönemde hipoksiye eğilimin artmasına yol açar $(1-3,14)$. Bu nedenle, obez hastaların anestezi yönetimi kişiye özel olarak planlanmaII, pre-operatif ve post-operatif dönemde meydana gelebilecek komplikasyonlara karşı hazırlıklı olunmalıdır.

DAA son yıllarda popülaritesi giderek artan bir anestezi tekniğidir. Yapılan çalışmalarda DAA kullanımının, düşük maliyet, azalmış çevre kirliliği ve solunum yolları fizyolojisinin daha iyi korunması gibi birçok faydası olduğu gösterilmiştir $(5,15)$. TGA'nın $0.6 \mathrm{~L} / \mathrm{dk}\left(0.3 \mathrm{~L} / \mathrm{dk} \mathrm{O}_{2}\right.$ ve $0.3 \mathrm{~L} / \mathrm{dk}$ $\mathrm{N}_{2} \mathrm{O}$ ) olarak uygulandığı genel anestezi altındaki 100 hastayla yapılan bir çalışmada, kaydedilen en düşük $\mathrm{FiO}_{2}$ değeri \% 31 olarak saptanmıştır. Bu çalışmada düşük akımdan yüksek akıma geçişi gerektiren herhangi bir olumsuzluk saptanmadığı belirtilmiştir (16). Bahar ve ark. TGA'nın $1 \mathrm{~L} / \mathrm{dk}$ olarak uygulandığı ve desfluran kullandıkları çalışmada hemodinamik parametrelerin stabil olarak seyrettiğini ve hiçbir hastada $\mathrm{FiO}_{2}$ nin \% 30'un altına düşmediğini belirtmişlerdir (17). Diğer bir çalışmada laparoskopik kolesistektomi sırasında, düşük akım ve yüksek akım anestezi uygulanan hastalar arasında $\mathrm{KAH}, \mathrm{OAB}$, $\mathrm{ETCO}_{2}$ ve Sp02 açısından anlamlı fark olmadığı bildirilmiştir (18). Yine Kazancıoğlu ve ark. TGA'yı 0.4 L/dk olarak uyguladıkları çalışmalarında, kontrollü hipotansiyon uygulanan septorinoplasti hastalarında DAA'nın serebral oksijen satürasyonunda herhangi bir farklılığa sebep olmadığını göstermişlerdir (19). Her ne kadar, yapılan çalışmalarda DAA'nın güvenli bir anestezi yöntemi olduğu belirtilmişse de, özellikle obez hastalarda DAA ile ilgili çalışmalar çok sınırlıdır. Obezlerde artmış metabolik intiyaç ve meydana gelen solunumsal değişiklikler, intraoperatif dönemde hipoksiye eğilimi artırabilir ve çeşitli komplikasyonların gelişimine zemin hazırlayabilir.

Tablo 4.Anestezi süreleri, desflurane tüketimleri ve MAK 1 ulaşma zamanı

\begin{tabular}{|c|c|c|c|c|c|c|}
\hline & $\begin{array}{l}\text { Grup 1 } \\
(n=25)\end{array}$ & $\begin{array}{l}\text { Grup 2 } \\
(n=25)\end{array}$ & $P$ & $\begin{array}{l}\text { Grup 3 } \\
(n=25)\end{array}$ & $\begin{array}{l}\text { Grup 4 } \\
(n=25)\end{array}$ & $P$ \\
\hline $\begin{array}{l}\text { Desflurane } \\
\text { tüketimi } \\
(\mathrm{ml})\end{array}$ & $\begin{array}{l}18 \pm \\
3.3\end{array}$ & $\begin{array}{l}36.8 \\
5.6\end{array}$ & $<0.001$ & $18.8 \pm 4.4$ & $37.3 \pm 7.2$ & $<0.001$ \\
\hline $\begin{array}{l}\text { Anestezi } \\
\text { süresi (dk) }\end{array}$ & $\begin{array}{l}53.8 \pm \\
10.9\end{array}$ & $\begin{array}{l}46.2 \\
9.8\end{array}$ & 0.014 & $59 \pm 13.6$ & $47.4 \pm 8.2$ & 0.002 \\
\hline $\begin{array}{l}\text { MAK1ulaş } \\
\text { ma zamanı } \\
\text { (dk) }\end{array}$ & $\begin{array}{l}3.7 \quad \pm \\
0.7\end{array}$ & $3.6 \pm 1$ & 0.953 & $3.4 \pm 0.8$ & $4.2 \pm 1.4$ & 0.031 \\
\hline
\end{tabular}

Tablo 5. İşlem sonrası komplikasyonlar

\begin{tabular}{|c|c|c|c|c|c|c|}
\hline & $\begin{array}{l}\text { Grup 1 } \\
(\mathrm{n}=25)\end{array}$ & $\begin{array}{l}\text { Grup } 2 \\
(\mathrm{n}=25)\end{array}$ & $\mathbf{P}$ & $\begin{array}{l}\text { Grup } 3 \\
(n=25)\end{array}$ & $\begin{array}{l}\text { Grup } 4 \\
(n=25)\end{array}$ & $\mathbf{P}$ \\
\hline Yok (\%) & $23(92)$ & $24(96)$ & 0.388 & $20(80)$ & $23(92)$ & 0.157 \\
\hline $\operatorname{Var}(\%)$ & $2(8)$ & $1(4)$ & & $5(20)$ & $2(8)$ & \\
\hline Bulantı-Kusma & $2(8)$ & - & & $4(16)$ & - & \\
\hline Bronkospazm & - & $1(4)$ & & - & $1(4)$ & \\
\hline Atelektazi & - & - & & $1(4)$ & $1(4)$ & \\
\hline Hipoksi & - & - & & - & - & \\
\hline
\end{tabular}

Akbas ve ark.'ları laparoskopik bariatrik cerrahi geçiren morbidobez (VKI $\geq 40)$ hastalarda düşük akım $(0.75 \mathrm{~L}$ /dk) ve normal akım anestezisinin (1.5 L/dk) serebral oksijenasyon ve bispektral indeks üzerindeki etkilerini karşılaştırmışlardır. Yazarlar, peri-operatif ve post operatif dönemde düşük akım anestezisine bağlı herhangi bir komplikasyona rastlamamışlar ve DAA'nın laparoskopik bariatrik cerrahiye giden morbidobez hastalarda güvenli bir yöntem olabileceği sonucuna varmışlardır (20). Ancak bu çalışmada laparoskopik bariatrik cerrahiye giden hastalar değerlendirildiği için sadece VKI $\geq 40$ olan morbid hastalar değerlendirilmiştir. Ek olarak, yazarlar bu çalışmada DAA için TGA'yı $0.75 \mathrm{~L} / \mathrm{dk}$ 'dan uygulamışlardır. Bizim çalışmamızda ise, VKI $\geq 30$ olan obez hastalar değerlendirilmiş ve TGA daha düşük bir değerden $(0.5$ L/dk) uygulanmıştır. Çalışmamızda da, DAA uygulanan obez hastalarda intraoperatif dönemde hipoksi veya herhangi bir komplikasyon gelişmediği görülmüştür. Bu sonuçlar, obez hastalarda DAA yönteminin güvenle kullanılabileceğini göstermektedir. Bilgilerimize göre çalışmamız, laparoskopik cerrahiye giden obez hastalarda TGA'nın $0.5 \mathrm{~L} / \mathrm{dk}$ 'dan uygulamasının güvenli olabileceğini gösteren ilk çalışmadır. 


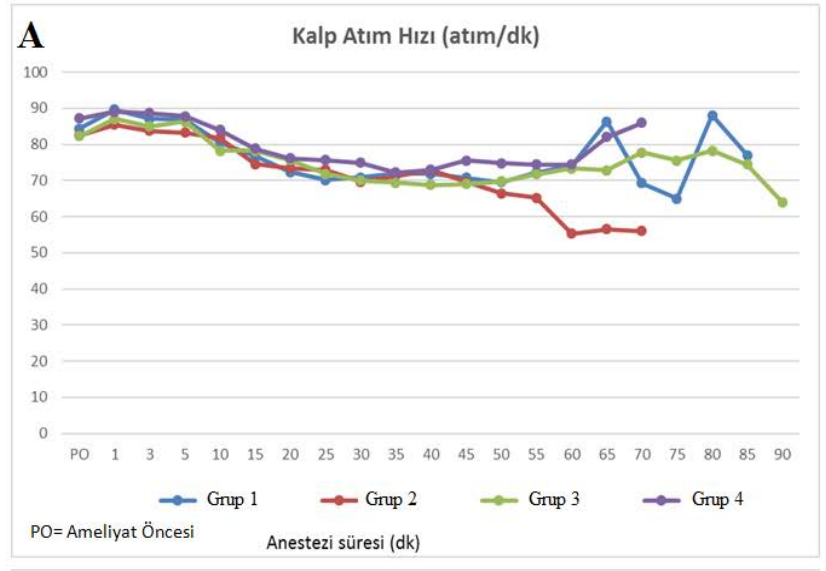

B
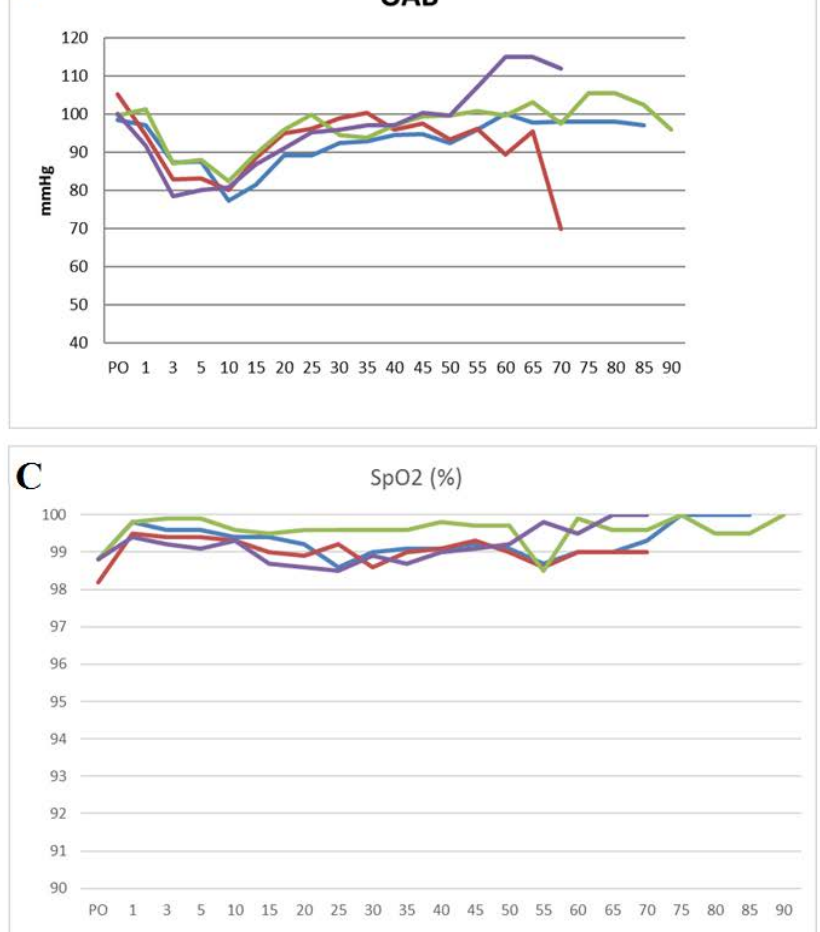

Şekil 1 A-C. Hastaların preoperatif ve intraoperatif dönemde kaydedilen hemodinamik parametreleri, A) kalp atım hızı, B) ortalama arter basıncı, C) oksijen saturasyonu

Yapılan çalışmalarda, TGA'nın 2 L/dk'dan 1 L/dk'a düşürülmesinin \%50 daha az desfluran kullanımına (21), TGA'nın 1 L/dk'dan 0.5 L/dk'a düşürülmesinin ise \%30 daha az desfluran kullanımına yol açtığı gösterilmiştir (22). Başka bir çalışmada ise, her bir hastadaki toplam ekonomik fayda düşünüldüğünde, daha az anestezik ajan kullanımından ciddi bir miktarda tasarruf sağlanabileceği belirtilmiştir (23). Çalışmamızda da, hem normal kilolu, hem de obez hastalarda DAA uygulamasının yaklaşık $\% 50$ daha az desflurane tüketimi ile ilişkili olduğu tespit edildi. Çalışmamızda elde edilen bulgular, literatür bilgileri ile örtüşmekte ve DAA uygulamasının daha az çevre kirliliği ve daha düşük maliyet ile ilişkili olduğu tezini desteklemektedir.

Laparoskopik kolesistektomi ameliyatlarında değişen solunumsal dinamikler nedeniyle hipoksi ve postoperatif atelaktazi görülme sıklığı artar. Artan oksijen kullanımı hipoksi oluşumu için geçen süreyi kısaltır. Yapılan çalı̧̧malarda obez hastalarda pulmoner kompliansın beklenen değerden \% 35 oranında düşük olduğu, artmış metabolik gereksinim nedeniyle solunum iş yükünün arttığı gösterilmiştir (24-26). Bu nedenlerden dolayı, obez hastalarda normal kilolu hastalara göre, laparoskopik işlemler sırasında solunum yolları ile ilişkili komplikasyonlar daha sık görülebilir (27). Çalışmamızda, DAA grubunda obez hastaların $\mathrm{O}_{2}$ alım miktarlarının normal kilolu hastalara göre daha yüksek olduğu görülmekteydi. Ancak gerek gaz analizatörleriyle inspiratuar oksijen miktarının takibi, gerekse pulse oksimetre ile periferik oksijen saturasyonunun takibi yapılarak hipoksiden korunulmuş ve hiçbir hastada hipoksi gelişmemiştir. Modern anestezi cihazlarıyla yapılan anestezi uygulamaları, hastaları bu komplikasyonlardan ve olası sonuçlarından korumaya yardımcı olmuştur. Çalışmamızın en büyük kısıtılığı hasta sayısının yetersiz oluşudur. Ek olarak, çalışmaya alınan olgularda anestezi derinliği hemodinamik yanıtlar ile değerlendirildi. Anestezi derinliğinin ölçülmesi için Bispectral index monitörizasyonunun yapılması çalışmamıza ek katkı sağlayabilirdi. Dahası, serebral oksijenizasyonun near-infrared spectroscopy ile takibinin yapılması daha efektif olabilirdi ancak cihaz kliniğimizde mevcut olmadığı için kullanılamadı.

Sonuç olarak, çalışmamızda, laparoskopik kolesistektomi uygulanan obez hastalarda düşük akım ve normal akım anestezisinin hemodinamik etkileri ve desflurane tüketimi üzerine etkileri incelenmiştir. Normal kilolu hastalarda olduğu gibi, obez hastalarda da DAA sırasında intraoperatif veya post-operatif dönemde herhangi bir komplikasyon gelişmediğini tespit ettik. Ek olarak, DAA uygulamasının daha az desflurane kullanımı ile ilişkili olduğunu tespit ettik. Çalışmamızdan elde edilen bulgular, DAA uygulamasının normal kilolu hastalarda olduğu gibi, obez hastalarda da güvenle kullanılabileceğini ve maliyeti düşürmede etkili bir yöntem olduğunu düşündürmektedir.

\section{Kaynaklar}

1- Lotia S, Bellamy CM. Anaesthesia and morbid obesity. Contin Educ Anaesth Crit Care Pain. 2008;8(5):151-6

2- Cullen $A$, Ferguson $A$. Perioperative management of the severely obese patient: a selective pathophysiological. Can J Anaesth. 2012;59:974-96.

3- Tuncalı B, Pekcan YÖ, Ayhan A, Erol V, Yılmaz TH, Kayhan Z. Retrospective Evaluation of Patients who Underwent Laparoscopic Bariatric Surgery. Turk J Anaesthesiol Reanim. 2018;46(4):297-304.

4- Baum JA, Aitkenhead AR. Low-flowanaesthesia. Anaesthesia. 1995;50:37-44.

5- BaumJ. Low Flow Anaesthesia: The Theory and Practice of Low Flow, Minimal Flow and Closed System Anaesthesia. 2nd ed. Butterworth-Heinemann; Oxford, Boston 2001.

6- Kılıç Y. A Reminder to Anesthesiologists: Low-FlowAnesthesia. J Clin Anal Med. 2016;7(suppl 2): 183-5.

7- Dohrn N, Sommer T, Bisgaard J, Ronholm E, Larsen JF. Difficult Tracheal Intubation in Obese Gastric Bypass patients. Obes Surg. 
2016; 26(11):2640-7.

8- Ortiz VE, Kwo J. Obesity: physiologic changes and implications for preoperative management. BMC Anesthesiology. 2016;15:97.

9- Lo HC, Wang YC, Su LT, Hsieh CH. Can early laparoscopic cholecystectomy be the optimal management of cholecystitis with gallbladder perforation? A single institute experience of 74 cases. Surg Endosc. 2012;26(11):3301-6.

10- Valenza F, Chevallard G, Fossali T, Salice V, Pizzocri M, Gattinoni L. Management of mechanical ventilation during laparoscopic surgery. Best Pract Res Clin Anaesthesiol. 2010;24(2):227-41.

11- Eichenberger A, Proietti S, Wicky S, Frascarolo P, Suter M, Spahn $\mathrm{DR}$, et al. Morbid obesity and postoperative pulmonary atelectasis: an underestimated problem. Anesth Analg. 2002;95(6):1788-92.

12- Dupont J, Tavernier B, Ghosez Y, Durinck L, Thevenot A, Moktadir-Chalons $\mathrm{N}$, et al. Recovery after anaesthesia for pulmonary surgery: desflurane, sevofluraneandisoflurane. $\mathrm{Br} J$ Anaesth. 1999;82:355-9.

13- Juvin $P$, Vadam C, Malek L, Dupont $H$, Marmuse JP, Desmonts JM. Postoperative recovery after desflurane, propofol, or isoflurane anaesthesia among morbidly obese patients: a prospective randomized study. Anesth Analg. 2000;91:714-9

14- Pelosi P, Croci M, Ravagnan I, Tredici S, Pedoto A, Lissoni A, et al. The effects of body mass on lung volumes, respiratory mechanics, and gas Exchange during general anesthesia. Anesth Analg. 1998; 87: 654-60.

15- Duymaz G, Yağar S, Özgök A. Comparison of Effects of Low-Flow Sevoflurane and Low-Flow Desflurane Anaesthesia on Renal Functions Using Cystatin C. Turk J Anaesthesiol Reanim. 2017;45(2):93-7.

16- Cherian A, Badhe A. Low-flowanaesthesia at a fixed flow rate. Acta Anaesthesiol Scand. 2009; 53: 1348-53.

17- Bahar S, Arslan M, Urfalioglu A, Gisi G, Oksuz G, Bilal B, et al. Low-flow anaesthesia with a fixed fresh gas flow rate. J Clin Monit Comput. 2019; 33(1):115-21.

18- Kupisiak J, Goch R, Polenceusz W, Szyca R, Leksowski K. Bispectral index and cerebral oximetry in low-flow and high-flow rate anaesthesia during laparoscopic cholecystectomy - a randomized controlled trial. WideochirInneTech Maloinwazyjne. 2011;6(4):226-30.

19- Kazancıoğlu L, Batçık Ş, Erdivanlı B, Şen A, Dursun E. Comparison of the Effects of Minimal and High-Flow Anaesthesia on Cerebral Perfusion During Septorhinoplasty. Turk J Anaesthesiol Reanim. 2019;47(1):12-16.

20- Akbas S, Ozkan AS. Comparison of effects of low-flowand normalflow anesthesia on cerebral oxygenation and bispectralindex in morbidly obese patients undergoing laparoscopic sleeve gastrectomy: a prospective, randomized clinical trial. Wideochirlnne Tech Maloinwazyjne. 2019;14(1):19-26.

21- Golembiewski J. Economicconsiderations in theuse of inhaled anestheticagents. Am J Health Syst Pharm. 2010;67(8 Suppl 4):S9-12. 22- Horwitz M, Jakobsson JG. Desflurane and sevoflurane use during low- and minimal-flow anesthesia at fixed vaporizer settings. Minerva Anestesiol. 2016; 82(2):180-5.

23- Jeong JS, Yoon SW, Choi SL, Choi SH, Lee BY, Jeong MA. Comparison of emergence times with different fresh gas flow rates following desflurane anaesthesia. J Int Med Res. 2014; 42(6): 1285-93.

24- Jose O, Miyoshi E, Claudia RF. The effects of abdominal opening on respiratory mechanics during general anesthesia in normal and morbidly obes epatients: A comparative study. Anesth Analg 2002; 94:741-8.

25- Salvadori A, Fanari P, Fontana M, Buontempi L, Saezza A, Baudo $S$, et al. Oxygen uptake and cardiac performance in obese and normal subjects during exercise. Respiration. 1999;66(1):25-33.

26- de Souza E Silva CG, Franklin BA, de Araújo CG. Influence of central obesity in estimating maximal oxygen uptake. Clinics. 2016; 71(11):629-34.

27- Coussa $M$, Proietti $S$, Schnyder $P$, Frascarolo $P$, Suter $M$, SpahnDR, et al. Prevention of atelectasis formation during the induc- tion of general anesthesia in morbidly obese patients. Anesth Analg. 2004:98(5):1491-5. 